\title{
Complutum
}

ISSN: 1131-6993

\section{Las mujeres del Museo Nacional de Antropología: una narrativa ausente en la Sala Mexica}

\author{
Melisa Muñoz Reyes ${ }^{1}$, Citlalli Reynoso Ramos ${ }^{2}$ y Mariano Castellanos Arenas ${ }^{3}$
}

Recibido: 26/03/2021 / Aceptado: 16/08/2021

Resumen. El Museo Nacional de Antropología (MNA), fundado en 1964, funge como un espacio de legitimación de la cultura nacional mexicana, un espacio de ideologización, creado por el Estado, que se reproduce por medio del discurso museográfico. La narrativa mostrada en el museo, específicamente en la sala mexica, es parcial y estereotipada, jerarquizando lo masculino sobre lo femenino. Este artículo tiene el objetivo de discutir la ausencia de las mujeres en la sala mexica del MNA como un síntoma de la ideología del Estado construida a través de un discurso patriarcal. La teoría de la decolonialidad funge como el eje central para la argumentación, la cual tiene como punto de partida criticar el binomio modernidad-colonialidad. Esto demuestra que el recorrido y la sala mexica forman parte de un pensamiento de tipo evolucionista lineal, dentro del cual se deja de lado la figura de la mujer mexica.

Palabras Clave: Museo Nacional de Antropología México, género y museos, decolonialidad y museos, nacionalismo y museos

[en] The women of the National Museum of Anthropology: a narrative of the absent at the Aztec exhibit

Abstract. Mexico's National Museum of Anthropology, founded in 1964, functions as a legitimation space for Mexican national culture, and an ideologization space that reproduces a particular museographic discourse. The discourse that is shown within the museum, specifically the Aztec room, is partial and stereotyped, hierarchizing masculine over feminine. This article seeks to show the relationship of what is shown in the museum and the decoloniality theory, the last of which comes from the modernity-coloniality binomial, this will show that the tour of the museum, and the Aztec room, are part of a lineal evolutionist thinking, within which the Aztec feminine figure is thrown to the side.

Key Words: museum, museum discourse, decoloniality, women.

Sumario. 1. Introducción. 2. Definición de términos. 3. La mujer en la sociedad azteca. 4. Las mujeres en la Sala Mexica del Museo Nacional de Antropología. 5. Conclusiones. Bibliografía.

Como citar: Muñoz Reyes, M. et al. (2021): Las mujeres del Museo Nacional de Antropología: una narrativa ausente en la Sala Mexica. Complutum, 32(2): 591-600.

\section{Introducción}

El Museo Nacional de Antropología (MNA), fue fundado en 1964 como uno de los recin- tos museográficos más importantes de México. Este museo, fue creado con el objetivo de exhibir el legado histórico mexicano, haciendo notar la diversidad étnica del país, y para cons-

\footnotetext{
1 Maestría en Territorio Turismo y Patrimonio en la Benemérita Universidad Autónoma de Puebla. Calle 2 Norte 1006 Cp. 72000 Centro Histórico de Puebla. melisa.munozrs@hotmail.com

2 Docente del Posgrado en Estudios Socioterritoriales Instituto de Ciencias Sociales y Humanidades "Alfonso Vélez Pliego" BUAP. Calle 2 Norte 1006 Cp. 72000 Centro Histórico de Puebla. citlali.reynoso@correo.buap.mx

3 Docente del Posgrado en Estudios Socioterritoriales Instituto de Ciencias Sociales y Humanidades "Alfonso Vélez Pliego" BUAP. Calle 2 Norte 1006 Cp. 72000 Centro Histórico de Puebla. castellanos.arenas@gmail.com
} 
truir y legitimar la cultura nacional mexicana (Schmilchuk 1995: 21). El museo es un espacio de ideologización, dado que reproduce un discurso nacionalista tanto en su arquitectura como en la distribución y contenido de sus exhibiciones (Maceira Ochoa 2008: 208). El discurso muestra ser parcial y estereotipado, referente al tema del género, dado que jerarquiza lo masculino sobre lo femenino, presentando así una visión con tintes androcéntricos (Maceira Ochoa 2008). Lo anterior se materializa en una presencia de lo femenino, y las actividades ligadas a este género, permeadas por un discurso androcéntrico.

Los museos son sitios complejos, que se posicionan en la intersección entre el trabajo científico y la exhibición (Forgan 2005: 572). Uno de los acercamientos más comunes para el estudio de los museos se concentra en los aspectos físicos de los edificios, su narrativa visual y la habilidad que éstos tienen para codificar el conocimiento en su forma material (Forgan 2005: 572). Estos edificios tienen un potencial transformativo enorme, y existen en sí mismos como una manifestación de cultura material y ciencia, y pueden decir mucho acerca del lugar que tiene el museo en la cultura, y cómo este papel cambia (Forgan 2005). Así, los estudios sobre museos analizan la cultura, tanto pasada, como presente.

Existen diferentes tipos de museos, su división se fundamenta en el tipo de patrimonio que éstos exhiben (Caballero Zoreda 1980). Se puede comprender que el Museo Nacional de Antropología funge como un museo de historia y un museo etnográfico, dada su división en dos importantes secciones: la arqueológica y la etnográfica. La sección arqueológica del museo tiene el objetivo de mostrar el pasado prehispánico mexicano, mientras que la sección etnográfica presenta todo tipo de objetos y temáticas relativas a las culturas indígenas contemporáneas existentes en el país. El MNA representa la exposición del pasado histórico nacional y la diversidad étnica del país.

Sobre el tema de mujeres y museos, es importante mencionar la investigación de Querol y Hornos (2015), quienes plantean la necesidad de que, en los museos, en este caso específicamente arqueológicos, se seleccione el género de las personas representadas con precaución, dando pie a renovaciones con especial cuidado en la representación de las mujeres del pasado. Igualmente cabe destacar la postura planteada por Querol (2014) dentro de la cual plantea que las mujeres se encuentran poco representadas en las exposiciones museísticas sobre Prehistoria o Arqueología. Querol (2014) deja clara la conclusión, por medio de análisis de museos arqueológicos e históricos en España, que la mujer se encuentra en posturas de clara sumisión, realizando trabajos que, dentro de la visión del presente, pueden ser entendidos como sin importancia, a pesar de ser sumamente importante para la sociedad del presente. Los trabajos citados anteriormente son prominentes en el campo del género femenino y su papel en los museos arqueológicos e históricos modernos.

En México, la mayoría de las investigaciones sobre museos y género enfatizan en la integración de la perspectiva de género en el discurso del museo (Muñoz 2019). Gándara (2017), desde la perspectiva de la arqueología de género, analiza la ausencia o presencia de la perspectiva de género en dos museos de yacimientos arqueológicos en México, mientras que Delgado Rojas (2017) estudia la incorporación del enfoque de género en proyectos curatoriales. Maceira Ochoa (2008), por su parte, analiza el discurso museológico de dos museos seleccionados (Museo Nacional de Antropología y Museo Nacional de Historia), para comprender las identidades y los roles de género, junto con las relaciones sociales y de poder entre hombres y mujeres. Esto lo hace al observar las actividades y espacios asociados a ellos y ellas, los valores y las representaciones propias de cada sexo y al establecer un orden predominante en base a esas observaciones. Este orden predominante de lo masculino sobre lo femenino, expuesto por Maceira Ochoa (2008), igualmente se deja entrever en investigaciones históricas, arqueológicas y antropológicas dadas en México, y el mundo.

Los museos, como espacios de valores históricos y de comunicación social, constituyen un medio para la visibilización de las mujeres. En el caso de los museos de arqueología, la cultura material posibilita el desarrollo de narraciones y discursos integradores, donde distintos grupos sociales, de edad y de género están presentes (Izquierdo Peraile, López Ruiz y Prados Torreira 2012). Así, la perspectiva de género empleada dentro de los museos pretende dar voz a los grupos olvidados por tanto tiempo, por el discurso museográfico, específicamente a las mujeres. Los museos incluyentes, que parten de la idea de inclusión dentro de la museografía, han sido el punto focal del Consejo Internacional de Museos (ICOM), de 
la United Nations Educational, Scientific and Cultural Organization (UNESCO, por sus siglas en inglés). El MNA es un museo nacional, que por definición se articula y representa al Estado. Dentro de este museo nacional el Estado se rinde homenaje a sí mismo, a la vez que funge como creador de identidad (Van Geert, Canals y González 2018: 187).

La perspectiva de género en el ámbito de la museología se configura como una herramienta esencial para asegurar la equidad entre mujeres y hombres, al hacer que el museo actúe como un centro de transmisión de la memoria de una comunidad, $y$, por lo tanto, de construcción de su cultura (Izquierdo Peraile, López Ruiz y Prados Torreira 2012: 271). El Instituto Nacional de Antropología e Historia (INAH) pretende, por medio de la convocatoria de la Guía Naranja, propuesta en el marco del Día Internacional para la Eliminación de la Violencia contra la Mujer, invitar al público a mirar a los museos desde una perspectiva de género y de derechos humanos, para visibilizar y cuestionar las diversas formas de discriminación y violencia contra las mujeres a través de sus piezas y discursos (INAH 2020). Sin embargo, con siete publicaciones en la red social Instagram bajo la etiqueta museos naranjas, de las cuales seis pertenecen al centro INAH, la convocatoria no contó con el impacto social que se habría propuesto.

Con lo anterior, se hace notoria la necesidad de observar al museo desde una perspectiva de género, por lo que el objetivo de esta investigación consistirá en analizar el rol de las mujeres en la sala mexica del Museo Nacional de Antropología (MNA) a través de una revisión bibliográfica, con el fin de comprender el trato que se les da a las mujeres en esta sala. Es importante mencionar que esta indagación se encuentra en proceso y corresponde al trabajo de tesis para obtener el grado de Maestría en Territorio, Turismo y Patrimonio por el Instituto de Ciencias Sociales y Humanidades de la Benemérita Universidad Autónoma de Puebla, México. Por lo que no se presentan resultados finales, sino reflexiones sobre el problema, un bosquejo de la aproximación teórica y algunos datos preliminares de análisis.

\section{Definición de términos}

Para los fines de esta investigación el museo se entiende como una institución sin fines lucrati- vos, permanente, al servicio de la sociedad y de su desarrollo, abierta al público, que adquiere, conserva, investiga, comunica y expone el patrimonio material e inmaterial de la humanidad y su medio ambiente con fines de educación, estudio y recreo, definición dada por el Consejo Internacional de Museos (ICOM, por sus siglas en inglés). La palabra museo proviene del griego mouseion, cuyo significado refiere a los templos dedicados a las musas, los cuales, además de cumplir con funciones religiosas, eran lugares de reunión para sabios, poetas y filósofos, siendo también el lugar donde se guardaban curiosidades pertenecientes al mundo de la ciencia y las artes (Cabrero 1987: 11).

A finales del siglo XIX comienza una nueva concepción del museo, entendido ahora como un lugar en el cual los objetos y los documentos debieran clasificarse y conservarse. Es en este momento donde el objetivo del museo se modifica para servir como recurso de enseñanza (Cabrero 1987: 15). Es en el mismo siglo XIX, donde el museo comienza a convertirse en un instrumento de atención y uso especiales, para fines e intereses propios de personajes influyentes en la vida cotidiana de la sociedad occidental, en otras palabras, el museo se habría convertido en un sector del mundo de los negocios, finanzas y relaciones públicas. Así, el museo se convierte en un objeto de deseo político y económico (Alonso 1999: 12).

Dentro del panorama planteado anteriormente, surgen nuevas inquietudes, gracias a una crisis existencial de la institución del museo, que requería una ciencia propia: la museología (Navajas Corral 2008: 2). Así, en 1946 se funda el Consejo Internacional de Museos (ICOM), con el objetivo de aglutinar las políticas y perspectivas museológicas de diferentes países que fueran parte de las Naciones Unidas, asesorando también a aquellos que no son integrantes de esta organización. Esta institución (ICOM), define a la museología como la rama de conocimiento que se ocupa del estudio del propósito y la organización de los museos, ligándola al estudio de la historia y los antecedentes de los museos, y su papel en la sociedad. Es a partir de la creación del ICOM que la museología, y sobre todo la Nueva $\mathrm{Mu}-$ seología, se entiende como una ciencia social, que debiera estar al servicio de la comunidad (Navajas Corral 2008: 2).

Para esta investigación se considera importante la comprensión de los conceptos de museografía y museología. La museografía consi- 
dera al museo como un objeto físico, y utiliza principios y normativas sistematizadas por la museología (Fernández 1999). La museología, por su parte, se ocupa de la teoría empleada en el museo como objeto físico, encargándose igualmente de la manera en que opera el mismo (Fernández 1999). Como se puede notar, estos dos conceptos son complementarios dentro del funcionamiento del museo, $y$, aunque mantienen el mismo objeto de estudio, responden a metas distintas (Hernández 1998).

El discurso museográfico, por su parte, no refiere sólo a la forma en que se organiza la construcción interna, el contenido y la función como un dispositivo productor de sentido. Este concepto refiere, más bien, al proceso de producción semiótica-discurso del museo (González Cirimele 2008). Al entender la semiótica como el estudio de los diferentes sistemas de signos que permiten la comunicación entre individuos, se puede comprender que el discurso museográfico se trata de aquellos signos y comunicados, que se presentan por medio de las exhibiciones y piezas del mismo museo. Ya que, como se había mencionado anteriormente, la museografía es aquella disciplina encargada de los aspectos técnicos del museo, dentro de los cuales se encuentran las exhibiciones físicas, el discurso museográfico, por tanto, será entendido como el mensaje que estas exhibiciones pretenden emitir, y las ideas inscritas en las mismas.

$\mathrm{Al}$ hacer uso del concepto de discurso museográfico, se hace alusión al proceso de producción semiótica, y el cómo los signos son usados con el fin de crear y transmitir sentidos y significados, y cómo estos se comunican al receptor. Lo anterior permite que se genere una producción de discursos que encapsulan distintos sentidos y significados. Así, este discurso museográfico, permeado por el discurso nacional impuesto, genera una memoria comunitaria, dentro de la cual se acepta una realidad.

El discurso nacional será entendido como aquel discurso dado por el Estado y relativo al nacionalismo. El nacionalismo por su parte será comprendido como un principio político que sostiene que debe haber congruencia entre la unidad nacional y la política, en otras palabras, el nacionalismo será una teoría de legitimidad política que prescribe que lo social no se contrapondrá a lo político (Gellner 2001: 13-4). Así, el discurso nacional se entenderá como aquel discurso dictado por el Estado acerca de lo que es la nación y los valores que esta nación mantiene.

La perspectiva de género hace alusión a una herramienta conceptual, la cual busca mostrar que las diferencias entre hombres y mujeres no se dan tan solo por la determinación biológica llamada sexo, sino también por diferencias culturalmente asignadas a los seres humanos por medio de la aplicación de la categoría de género. Así, la perspectiva de género implica el reconocimiento de la distinción entre la diferencia biológica, sexual, y las atribuciones, ideas, prescripciones sociales y representaciones, que se construyen al referenciar esta diferencia sexual, lo que se conoce comúnmente como: género.

Es por medio de este reconocimiento que se puede analizar un museo a través de una perspectiva de género. Lo anterior, igualmente implica el reconocimiento del discurso museográfico dentro de otra categoría teórica: la decolonialidad. La decolonialidad es un movimiento epistemológico latinoamericano, centrado en desenredar la producción del conocimiento dado desde una episteme primariamente eurocéntrica (Mignolo 2007: 27). Este movimiento critica la percepción universal de la superioridad del conocimiento del oeste, en otras palabras, el europeo. El pensamiento decolonial emerge desde la fundación del binomio modernidad-colonialidad, dado que es la contrapartida de éste (Mignolo 2007: 27).

Para poder comprender el binomio modernidad-colonialidad, es necesario comprender la modernidad y la colonialidad como conceptos singulares. La modernidad refiere a los modos de vida social y organizacionales surgidos en Europa a partir del siglo XVII. Éstos, posteriormente habrían de ampliar su zona de influencia de manera global, por medio de la conquista de territorios externos a los europeos. La colonialidad, por su parte, surge del imperialismo del siglo XIX, al difundirse el ideal imperialista. Dentro del colonialismo moderno, se dio un control directo de las potencias centrales (europeas), sobre los territorios y pueblos colonizados (Quintero 2010). La colonialidad como concepto se liga fuertemente con la noción de colonialidad del poder, término dispuesto por Quijano (2002), y usado para caracterizar este patrón de dominación global, propio de un sistema-mundo moderno y capitalista que se originó con el colonialismo europeo a principios del siglo XVI (Quintero 2010: 3). Este sistema mundo, según Wallerstein (1974), refiere a las relaciones económicas 
mundiales, las cuales forman un sistema global dentro del cual las naciones más desarrolladas, en este caso las naciones europeas, explotan la mano de obra y los recursos naturales de aquellas naciones en vías de desarrollo, en otras palabras, las naciones conquistadas.

\section{La mujer en la sociedad azteca}

Las actividades femeninas se entenderán como aquellas actividades ligadas a las mujeres dentro de la cultura mexica. Se sabe que la mujer mexica participaba en actividades de agricultura, tareas domésticas, como parteras, elaboración de alimentos y prendas, entre otras. Las mujeres aztecas eran responsables de atender a los animales de crianza, e igualmente eran encargadas de llevar al mercado la ropa, comida y otros artículos para su venta o intercambio (Phillips 2011). Dentro del hogar, una de las funciones más importantes para la mujer mexica era moler el maíz para elaborar tortillas (Madsen 1960). Las mujeres podían participar en diferentes profesiones dentro de la civilización azteca, tales como: sacerdotisas, curanderas, brujas, artesanas y tejedoras (Keen 2019; Powers 2005).

Las actividades que desarrollaban las mujeres dentro de esta civilización delatan por sí mismas la importancia que la mujer tenía dentro de la sociedad azteca, y más aún a nivel simbólico, dada la dualidad de deidades que se muestra dentro del panteón azteca. Se sabe que la mitología azteca mantenía una gran cantidad de dioses, de los cuales algunos eran femeninos. Estas diosas comúnmente se relacionaban con fertilidad, muerte en parto, protectoras de parto, entre otras. Rodríguez-Shadow (2000), en su libro titulado La mujer azteca, menciona que dentro del Códice Azcatitlán se muestra a las mujeres, durante el viaje se peregrinación azteca, constituyendo la retaguardia, ayudando a transportar el equipo y los alimentos. Según los datos que proporcionan las fuentes históricas y los códices antiguos, para el momento de la peregrinación ya se había abandonado la vieja religión mesoamericana que se basaba en la adoración de la pareja primordial: Ometecutli y Omecíhuatl, el señor y la señora de la dualidad.

Al llegar a la época en que los aztecas habrían consolidado su asentamiento en Tenochtitlán era notorio que la mujer no guardaba una condición de homogeneidad, dada su posi- ción cambiante de acuerdo con la clase social a la que perteneciera, su edad, el momento de su ciclo vital dentro de la familia y sus características individuales. En términos generales, la situación de la mujer mexica era de sometimiento y subordinación respecto a sus contrapartes masculinas, dado que las mujeres habrían sido sustraídas de aquellas actividades que implicaban riqueza, poder y prestigio, como el sacerdocio, el comercio, la guerra y la cacería ritual (Rodríguez-Shadow 2000: 52). Así, las actividades femeninas serían relegadas a aquellas actividades domésticas, o lo que Habermas (1987) llamaría el espacio privado.

En cuanto a la mujer en su situación de noble, Rodríguez-Shadow (2000: 53) menciona que estas mujeres pertenecían al estrato dominante y compartían con sus contrapartes masculinas algunos de los privilegios dados por su prominente posición, como la posibilidad de heredar tierras. Sin embargo, a pesar de contar con sangre noble, estas mujeres no podrían tener acceso al poder político, ni derecho de heredarlo, dado que ella era un mero agente que transmitía el poder y los privilegios clasistas por medio del matrimonio y parto. Con lo anterior se pueden comprender las diferentes situaciones de la mujer mexica: como parte de la clase noble, como campesina, como ama de casa y como esclava.

La situación más común para una mujer en la época azteca habría sido el trabajo doméstico, que se encuentra ligado a aquellas prácticas cotidianas y actividades específicas que la mujer llevaría a cabo en el hogar y que habrían sido destinadas a la reproducción de bienes y valores de uso que permitieran el mantenimiento de la fuerza de trabajo (RodríguezShadow 2000: 69). En la sociedad mexica, las tareas del hogar eran consideradas labores fundamentalmente femeninos e impuestos por una división sexual y de clase estricta en cuanto al trabajo, sustentada y legitimada por elementos estructurales e ideológicos de dicha sociedad (Rodríguez-Shadow 2000).

Con lo expuesto anteriormente se puede deducir que los artefactos ligados al trabajo del hogar estarían ligados a actividades femeninas. Al trabajar principalmente en el interior del hogar, las mujeres habrían dejado su marca en el tiempo, por medio de artefactos que representaran actividades comunes, tales como: hilar, tejer algodón, atender a los animales ganaderos, hacer truques con los bienes elaborados en casa, moler maíz y hacer tortillas, el 
embarazo y parto y atender a los infantes del hogar.

Es importante mencionar las características que incluye el patriarcado: Está compuesto de usos, costumbres, tradiciones, normas familiares, hábitos sociales, ideas, prejuicios, símbolos e incluso leyes cuya enseñanza asegura su transmisión generacional (Snaidas 2009). Define roles o estereotipos sexuales por el mecanismo de la ideología, naturalizándolos y universalizándolos (Fernández Carballo y Duarte Cordero 2007). Históricamente fue la primera estructura de dominación y subordinación, fue la primera estructura de dominación y subordinación de la historia, y aún hoy sigue siendo un sistema básico de la dominación: el más poderoso y duradero de desigualdad y el que menos se percibe como tal.

\section{Las mujeres en la Sala Mexica del Museo Nacional de Antropología}

Citando a la página de internet del Instituo Nacional de Antropología e Historia (2020), esta es la sala más representativa del museo, y una de las que más piezas arqueológicas tiene exhibidas. Esta página explica que la muestra representa el poderío y la importancia que alcanzó, durante el periodo Posclásico Tardío (1250-1521 d.C.) la sociedad mexica. Lo anterior se puede notar en la cantidad de objetos localizados en la sala, en el tamaño mismo de la sala y su ubicación dentro de la espacialidad del museo.

El recorrido comienza con una explicación sobre la extensión del imperio mexica, se debe comentar que ha sido cuestionado el uso de la palabra imperio para definir a esta cultura. Igualmente se encuentra una cédula que explica "El mundo mexica". Junto a estas descripciones se encuentra el Teocalli de la Guerra Sagrada, un monolito mexica que parece ser una representación a escala de un templo o el icpalli (silla real), del líder del pueblo azteca. Los simbolismos que se encuentran dentro del mismo aluden a la ideología del poder mexica y el principio religioso de la guerra sagrada (Carr 2008). Así se puede percibir que el fin museográfico de esta sala, desde el inicio de esta, corresponde a la demostración del poder que mantenía esta cultura prehispánica. Cabe mencionar que, desde la entrada, se visualiza la Piedra del Sol, al fondo, uno de los elementos más significativos de esta sala.
Entre las figuras más importantes de esta sala se encuentran la Piedra de Tizoc, la cual se cree era una escultura dedicada a ser un monumento a la victoria militar, dado que se pueden apreciar junto a las figuras de los guerreros los glifos de las regiones que éstos habrían conquistado o derrotado (Neaves 2005). La estatua de Coatlicue (diosa de la fertilidad en la mitología mexica), la cual fue descubierta en 1790. Cabe mencionar que el evento de la estatua de Coatlicue muestra el momento en que los novohispanos intentaban convertir en algo explicado y comprendido para ellos a un monumento parte vivo de las creencias y la religiosidad de las poblaciones indígenas. Lo anterior quiere decir que el descubrimiento de esta estatua comenzó el interés criollo por apropiarse del pasado indígena, rechazando la cultura viva y las tradiciones religiosas de los indígenas contemporáneos (Florescano 1997: 153)

El Xochipilli, estatua dedicada al dios del amor, los juegos, la belleza, las flores, el maíz, el placer y la ebriedad sagrada, igualmente se impone como una de las figuras más importantes de esta sala, la cual habría sido parte de la colección personal del historiador Alfredo Chavero, quien habría de donarla al museo tiempo después (López Luján 2011). Una reproducción del Códice borbónico, perteneciente a los códices mexicas precolombinos, igualmente tiene un lugar importante en el recinto, este códice fungió como un calendario y no se localiza su forma original dentro de la nación mexicana. Otra pieza que se muestra en reproducción, es el penacho de Moctezuma, el cual es un tocado de plumas de quetzal engarzadas en oro utilizado por el tlatoani mexica, y que se localiza actualmente en el Museo de Etnología de Viena, en Austria.

En cuanto a la espacialidad, en comparación con otras salas, los objetos ocupan casi todo el espacio disponible, y cuentan con cédulas de diferentes formatos a diferencia de otras salas. Esto puede significar un intento consciente por diferenciar esta sala de las demás, con el fin de demostrar su importancia. Igualmente, la sala en sí es un homenaje al poder por medio de representaciones de guerra y de conquistas, mostrando al pueblo mexica como fuertes guerreros, e induciéndolos al imaginario nacionalista como un eje de representación de poder estatal.

E1 MNA ha sido asumido como un espacio de ideologización por medio del discurso 
empleado en sus exhibiciones (Maceira Ochoa 2008: 208), y al mismo tiempo generando una invisibilización del rol de las mujeres dentro del mismo. El género, como tal, no cuenta con una relación directa con el discurso museográfico, dado que para comprender esta relación es necesario desmantelar y pretender ver esta representación de la mujer. El recorrido devela el discurso museográfico, lo que implica la observación de la puesta en escena y el montaje dado dentro del museo, permitiendo percibirlo como un hecho movible. Este discurso se materializa por medio del poder, el discurso nacional detrás del mismo al inmiscuirse dentro del discurso museográfico y parece mostrar una imposición del género masculino sobre el femenino.

Cuando se mencionan estas estructuras históricas, bajo las cuales las mujeres siguen sufriendo discriminación, se refiere al pensamiento colonial europeo, donde la mujer no tenía cabida dentro de la vida pública (Habermas 1987). La discriminación de las mujeres se produce de manera individual y colectiva, deliberada e inconsciente, dado que está tejida en las costumbres y tradiciones dadas históricamente (Lamas 1996), y se argumenta que estas costumbres comienzan con la aceptación del marco dado por el binomio modernidad-colonialidad.

Las relaciones de poder que se desarrollan en una sociedad patriarcal capitalista, como lo es México, son de dominación y subordinación entre los géneros (Villareal 2003). Han existido diferentes movimientos sociales por la igualdad y los derechos, tal como el movimiento feminista, que han evidenciado y denunciado desde los años sesenta el sesgo de marcado carácter androcéntrico que tiende a mostrarse dentro de las instituciones museísticas (Verdú y Azcárate, 2018). Como mencionan Izquierdo Peraile, López Ruiz y Prados Torreira (2012), existen muchas imágenes de mujeres que se representan en los museos, éstas transmiten la idea de que se trata de individuos pasivos, secundarios, que desarrollan funciones supuestamente naturales, y ahondan en la idea de que los roles de género son inmutables, a lo largo de la historia y en todas las culturas.

Los museos se aprecian como una institución eficaz para la transmisión de cultura e historia nacional, las cuales, al ser interiorizadas como propias, forman una parte intrínseca del ente socializado (Rodríguez-Shadow 2017: 249). Estas instituciones son capaces de crear un relato acerca de una sociedad pasada, dejando claros los espacios y las actividades a los cuales se atenía cada género. Lo anterior se logra por medio de la creación de un discurso museográfico que, aunque parte del discurso nacionalista, deja entrever los ideales y preceptos de la actual sociedad mexicana, dentro de la cual se puede argumentar que presenta una fuerte inclinación patriarcal. Así, como menciona Rodríguez-Shadow (2017: 251), sólo la transformación del discurso museográfico podrá permitir el abandono de estas posturas androcéntricas que se hacen notar dentro de las salas de los museos mexicanos en general y, específicamente, de la sala mexica del MNA.

Se argumenta que, en el museo, dada su historia y su relación con los proyectos postrevolucionarios mexicano, muestra un legado patriarcal, que llega a la modernidad por medio de esta misma institución. Así, el museo sigue siendo una elaboración cultural que legitima un pensamiento de género (raza y clase), otorgando un origen natural a algo que no lo tiene: la dominación de un género ante el otro (Riaño 2020). Una de las teóricas androcéntricas occidentales, parte del binomio modernidadcolonialidad, considera que en la cultura está muy marcada la separación de lo femenino y lo masculino, evidenciado por la desvalorización, menosprecio y sumisión, donde la mujer es víctima (Díaz 2015).

Existen numerosos estudios que pretenden dar un giro y evidenciar el importante papel social, político y cultural de las mujeres, desentrañando una realidad histórica que no había sido vista gracias a la presencia de una fuerte carga ideológica androcéntrica (Díaz 2015). En la antigüedad podemos observar distintas representaciones de mujeres con papeles importantes dentro de su sociedad, especialmente en la cultura maya. Dentro de la cultura mexica, se pueden observar su participación en la configuración de la cosmovisión, dado que, importantes diosas como Xochiquetzal, Tonantzin, Coatlicue, Chicomecóatl. Teteoinan, Chalchiuhtlicue, Coyolxauhqui y Xilonen colman el panteón de dioses aztecas, no rivalizando con los dioses varones, sino que, complementando el equilibrio del universo, con lo que transparentaban la dualidad con la que se entiende su cultura (Díaz 2015). Esta dualidad muestra la igualdad que se tenía dentro del panteón mexica, que podría a su vez representar la igualdad que mantenían los géneros dentro de la misma sociedad. Sin embargo, el 
mundo azteca consideraba a las mujeres en un rol de dependencia ante los hombres, gracias a lo cual su ámbito de desarrollo era el hogar y la crianza (Díaz 2015). ). En la sala mexica se muestra guerra, poder y conquista, pero no se muestra el aspecto del hogar de esta sociedad, dado que no cumple con la finalidad de mostrar el poder en el ámbito público, político y del Estado del pueblo mexica.

Dentro de esta búsqueda del Estado por promover la idea de poder (idea vinculada con el género masculino), se muestra una representación estrecha y rígida de los pueblos habitantes de Mesoamérica, dejando fuera las cuestiones de la esfera del hogar y concentrándose meramente en la vida militar y pública, de la cual, por lo general, tendrían control los hombres. La teoría del rizoma, dada por la disciplina de la filosofía corresponde a un modelo descriptivo o epistemológico en el que la organización de los elementos no sigue líneas de subordinación jerárquica, con una base o raíz que da origen a múltiples ramas, sino que cualquier elemento puede afectar o incidir sobre otro (Deleuze y Guattari 1972: 13).

El rizoma central, que en este caso sería la cultura mexica (según la ideología del Estado), no permite las unidades, sino dimensiones asignificantes y asubjetivas, de direcciones quebradas (Deleuze y Guattari 1972). Lo anterior termina por crear un proceso unidireccional, borrando lo complejo del mundo real y reduciéndolo a un mero sistema donde existe una raíz bajo la cual se funda el pensamiento nacionalista, con ramas que no inciden dentro de esta raíz. Así, se comprende que el museo, como ese árbol concebido por Deleuze y Guattari (1972), crea un modelo estructural que tiene como lógica principal aquella de reproducción. En el caso del museo, esta reproducción será la reproducción de la misma ideología impuesta por el Estado, y los elementos no mostrados, tales como las actividades de mujeres y las mujeres mismas, son aquellas ramas rotas, dado que no cumplen con el fin de la raíz. Así, se puede comprender que la puesta en escena del MNA se encuentra guiado por los principios de un sistema patriarcal.

\section{Conclusiones}

El MNA constituye la representación del sentir de los grupos de poder político e intelectual acerca del nacionalismo, y dentro de sus muros se define al mexicano para definir a la nación (Sanz Jara y Valle de Frutos 2015: 117-118). La narrativa del museo vista desde su recorrido, hace clara la concepción de lo que es ser mexicano y lo que debe ser considerado importante para estos fines. El indígena prehispánico ya no está, es simbólico y forma parte de un imaginario, este indígena es un conjunto vacío que todos rellenamos en nuestra mente de manera individual, lo anterior siendo complementado por las imposiciones del Estado que pretende encarnar al indígena prehispánico como un ideal bajo el cual todos entendamos lo que es el ideal nacionalista mexicano (Sanz Jara y Valle de Frutos 2015: 122).

El impacto monumental del museo se percibe únicamente en la planta baja, donde se encuentran las colecciones arqueológicas que muestran el pasado prehispánico de la nación. Como menciona Ruffer (2014: 101), la monumentalidad otorga la posibilidad de teatralizar el pasado indígena, separando a su vez el objeto-ruina, la historia nacional y los pueblos indígenas de hoy, como si se estuviese hablando de cuestiones completamente distintas. El museo re-contextualiza un conjunto de objetos para emitir un mensaje concreto, colocando en el mundo a la nación y mostrando la identidad nacional al tiempo de construirla (Sanz Jara y Valle de Frutos 2015: 119).

En cuanto al orden de las salas y del mismo recorrido del museo, se encuentra muy presente el evolucionismo (Sanz Jara y Valle de Frutos 2015: 120), lo anterior permite que el visitante, al recorrer el itinerario del museo reconozca una evolución que ultimadamente lleva a la sala mexica, reconociendo a esta cultura como el epítome del ser mexicano. Tal como mencionan Sanz Jara y Valle de Frutos (2015: 121), la manera en que se ordena el espacio parece estar inspirada en una jerarquización, en la cual habría una meta, en este caso, la cultura mexica, que tendría un mayor grado de desarrollo. Lo anterior permite el entendimiento, dentro del imaginario que impone el museo, de que las demás culturas, previas a la cultura mexica, son fases subdesarrolladas que permiten llegar al desarrollo superior de esta última cultura.

Así, el recorrido mismo promueve el uso de los mitos prehispánicos para conformar un imaginario nacionalista, partiendo de la necesidad postrevolucionaria de unificación de un pueblo heterogéneo, que demandaba ser visto por el estado. Este imaginario teatraliza el pasado para generar una aceptación por parte del 
público sobre su propio pasado. Por otro lado, el indio contemporáneo se encuentra relegado espacialmente, los mismos accesos, las escaleras que llevan a las salas etnográficas, se encuentran escondidas. Esto se debe a que, como mencionan Sanz Jara y Valle de Frutos (2015: 134), la importancia del componente indígena en el nacionalismo lo representa mejor el pasado precolombino, con su grandeza y sus valores, más que el indígena contemporáneo, el cual se percibe como mezclado con lo español primero y con lo occidental después.

Es importante comprender que, dentro de esta representación estrecha y rígida del nacionalismo dentro del museo, se dejan fuera algunas cuestiones. Esto se debe a que muestran lo que se quiere ver, o en este caso específico, lo que el Estado quiere que se vea. En la filosofía existe una teoría referente al rizoma, desarrollada por Deleuze y Guattari, quienes explican que un rizoma es un modelo descriptivo o epistemológico en el que la organización de los elementos no sigue líneas de subordinación jerárquica, con un base o raíz dando origen a múltiples ramas, sino que cualquier elemento puede afectar o incidir en cualquier otro (Deleuze y Guattari 1972: 13). Se puede argumentar que, el MNA, aparte de conformar un sistema patriarcal, mantiene un cimiento rizomático, donde cualquier ideología afirmada dentro de un elemento incide en la concepción de otros elementos que conforman el museo, sin importar la posición que estos mantengan en términos jerárquicos.

\section{Bibliografía}

Alonso, L. F. (1999): Introducción a la Nueva Museología. Alianza, Madrid.

Caballero Zoreda, L. (1980): El museo: funciones, personal y su formación. B. Anabad, 30: 377-385.

Cabrero, M. T. (1987): El Museo Universitario de Antropología. Instituto de Investigaciones Antropológicas, México D.F.

Deleuze, G. y Guattari, F. (1972): Capitalisme et schizophrénie. L'Anti-Edipe, Paris.

Delgado Rojas, C. (2017): El museo de la mujer o la mujer en el museo: estrategias de visibilización e incorporación del enfoque de género en proyectos curatoriales. s.l.:Maestría en Museología y Gestión del Patrimonio.

Díaz, L. B. (2015): La mujer gobernante en la época prehispánica. Vida Científica. Boletín Científico de la Escuela Preparatoria No. 4, 3(4).

Fernández, L. (1999): Museología y Museografía. Ediciones del Serbal, Barcelona.

Fernández Carballo, R. y Duarte Cordero, A. (2007): Origen, consolidación y vigencia de los preceptos patriarcales asignados al género femenino y masculino y su refractación en los cuentos. Revista InterSedes, 6(10).

Florescano, E. (1997): El patrimonio nacional de México. CONACULTA, Ciudad de México.

Forgan, S. (2005): Building the museum: knowledge, conflict, and the power of place. Isis, 96(4): 572-585.

Gándara, M. (2017): El enfoque de género -o su ausencia- en dos museos de yacimientos arqueológicos en México. Museos arqueológicos y género. Educando en igualdad, 248-272.

Gellner, D. N. (2001): How should one study ethnicity and nationalism?. Contributions to Nepalese Studies, 28(1): 1-10.

González Cirimele, L. (2008): Funcionamiento del poder y del saber en el discurso/texto museográfico comunitario. Cuicuilco, 15(44): 135-159.

Habermas, J. (1987): Teoría de la acción comunicativa. Taurus, Madrid.

Hernández, F. H. (1998): Manual de Museología. Editorial Síntesis, Madrid.

Izquierdo Peraile, I., López Ruiz, C. y Prados Torreira, L. (2012): Exposición y género: El ejemplo de los museos de Arqueología. SIAM, Series Iberoamericanas de Museología: 271-285.

Keen, B. (2019): Latin American Civilization: History and Society, 1492 to the present. Routledge, Londres.

Lagunas, C. y Ramos, M. (2007): Patrimonio y cultura de las mujeres: jerarquías y espacios de género en museos locales de generación popular y en institutos oficiales nacionales. La Aljaba, 11: 119-140.

Lamas, M. (1996): La perspectiva de género. [URL: http://www.inesge.mx/pdf/articulos/perspectiva genero.pdf]. Acceso el 12/04/2021.

López Luján, L. (2011): Culturas del Centro de México en el Posclásico Tardío. Catálogo Esencial, Museo Nacional de Antropología (L. López Luján, ed.): 165-188.

Maceira Ochoa, L. (2008): Género y consumo cultural en museos: análisis y perspectivas. La ventana: revista de estudios de género, 3(27): 205-230. 
Madsen, W. (1960): The Virgin's Children. Life in the aztec village today. University of Texas Press, Austin.

Mignolo, W. D. (2007): Delinking: The rhetoric of modernity, the logic of coloniality and the grammar of de-coloniality. Cultural Studies, 21(3): 449-514.

Muñoz, E. A. (2019): La presencia o ausencia de la perspectiva de género en dos exhibiciones permanentes del Museo Nacional de Antropología (MNA), México: un ejercicio diagnóstico mediante el análisis de sus cedularios. Intervención (México DF), 10(19): 51-63.

Navajas Corral, O. (2008): Una Nueva Museología. Revista Nueva Museología.

Neaves, M. T. (2005): Los glifos toponímicos en las esculturas conocidas como Piedra del Ex Arzobispado y Piedra de Tizoc. Universidad Autónoma de México, Ciudad de México.

Phillips, L. H. (2011): I am Alone. I am a Woman. What are my children going to eat?. Domestic Workers and Family Networks. South African Review of Sociology, 42(2): 29-44.

Powers, K. V., 2005. Women in the crucible of conquest: the gendered genesis of Spanish American society, 1500-1600. New Mexico: UNM Press.

Querol, M. A. (2014): Museos y Mujeres: la desigualdad en Arqueología. Arqueoweb: Revista sobre Arqueología en Internet, 15(1): 270-280.

Querol, M. A. y Hornos, F. (2015): La representación de las mujeres en el nuevo Museo Arqueológico Nacional: comenzando por la Prehistoria. Complutum, 26(2): 231-238.

Quijano, A. (2002): Colonialidad del poder, globalización y democracia. Revista de Ciencias Sociales de la Universidad Autónoma de Nuevo León, 4(7): 1-23.

Quintero, P. (2010): Notas sobre la teoría de la colonialidad del poder y la estructuración de la sociedad en América Latina. Des/colonialidad y Buen Vivir. Un nuevos debate en América Latina: 193-216.

Riaño, P. H. (2020): Las invisibles: ¿Por qué el Museo del Prado ignora a las mujeres?. Capitán Swig Libros, España.

Rodríguez-Shadow, M. (2007): Las mujeres en Mesoamérica prehispánica. Universidad Autónoma del Estado de México.

Rodríguez-Shadow, M. (2017): Las imágenes femeninas en la sala del Preclásico del Museo Nacional de Antropología e Historia. Museos arqueológicos y género: educando en igualdad (L. P. Torreira y C. L. Ruiz, eds.), Ediciones Universidad Autónoma de Madrid, Madrid: 242-273.

Sanz Jara, E. y Valle de Frutos, S. (2015): Etnicidad y nacionalismo en el Museo Nacional de Antropología de México: lecturas desde su espacio físico y virtual. Documentos de Trabajo (IELAT, Instituto Universitario de Investigación en Estudios Latinoamericanos), 77: 111-147.

Schmilchuk, G. (1995): Historia, antropología y arte. Notas sobre la formación de los museos nacionales en México. RUNA, archivo para las ciencias del hombre, 22(1): 21-38.

Snaidas, J., 2009. El feminicidio en América Latina, historia y perspectivas. V Jornada de Jóvenes Investigadores, Buenos Aires.

Van Geert, F., Canals, A. y González, Y. N. (2018): La representación multicultural del indígena en los museos de comunidad latinoamericanos. Boletín americanista, 2(77): 185-202.

Verdú, S. y Azcárate, A. A. (2018): Educación con perspectiva de género en museos españoles. Enfoques y discursos. Géneros, 7(1): 1531-1555.

Villareal, A. L. (2003): Relaciones de poder en la sociedad patriarcal. Revista Espiga, 4(7): 75-90.

Wallerstein, I. (1974): Dependence in an interdependent world: the limited possibilities of transformation within the capitalist world economy. African Studies Review: 1-26. 